\title{
LA PUBLICIDAD EN EL PUNTO DE VENTA: SU REALIDAD Y TENDENCIAS.
}

\section{ADVERTISING POINT OF SALE: YOUR REALITY AND TRENDS.}

\section{AUTORA}

\section{María Robles López}

Social Media Manager en Sync Intertainment. Licenciada en Publicidad y RR.PP. por la U. San J orge de Zaragoza (España)

maria_robles81@hotmail.com

\section{RESUMEN}

Se han realizado numerosos estudios sobre la eficacia de la publicidad en el punto de venta, llamada PLV, que demuestran el gran impacto que este tipo de acciones tienen en las ventas. Debido a sus características como medio no convencional de comunicación, permite a los anunciantes establecer una relación más directa con los consumidores y personalizar el mensaje. Aunque la publicidad en el punto de venta cada vez es mayor, no se le otorga la importancia que verdaderamente tiene.

\section{PALABRAS CLAVE}

PLV - Marketing - Publicidad - Consumidor - Impacto - Medios no convencionales.

\section{ABSTRACT}

Numerous studies measuring the effectiveness of publicity materials (known as PLV) in commercial sales points (commercial centres, outlets etc.) have been undertaken, 
and have identified the important impact of these activities on sales. Due to non conventional characteristics of this medium of communication, it permits the advertiser establish a more direct relationship with the consumer and personalize the message. Even though the use of PLV publicity in commercial sales points is ever growing, its true value isn't adequately recognised.

\section{KEY WORDS}

PLV - Marketing - Advertising - Consumer - Impact - Below the line media.

\section{ÍNDICE}

Introducción

1. Marco teórico

La publicidad no convencional o bellow the line

1.1.1. La BTL

1.1.2. La clasificación y características de los medios no convencionales.

1.1.3. La BTL en números

1.1.4. Tendencias de la BTL

1.2. Marketing

1.2.1. Definición

1.2.2. Evolución del marketing

1.3. Publicidad en el punto de venta o PLV

1.3.1. ¿Qué es la PLV?

1.3.2. La PLV en números

1.3.3. Los límites de la PLV en el marketing at retail

1.3.4. La PLV desde el Neuromarketing

1.3.5. El impacto de la PLV 
2. Hipótesis

3. Objetivo

4. Metodología

5. Resultados de la investigación

5.1. Características de la PLV

5.2. Definición de la PLV

5.3. Clasificación de las PLV

5.4. Datos de las formas de PLV observadas

6. Conclusiones

7. Bibliografía

8. Webgrafía

9. Documentos sonoros

\section{Anexos}

10.1. Un pequeño recorrido por las agencias dedicadas a la PLV

10.2. ¿Cómo se puede medir la eficacia y el impacto de la PLV?

11. Vocabulario

12. Listados de las que componen los resultqados

13. Resultados completos

14. Propuestas para una optimización de la PLV

\section{Introducción}

La saturación publicitaria a la que la población se ve sometida en su vida diaria a través de medios convencionales - principalmente-, lleva a la mente humana en busca de nuevos caminos de exploración para hacer llegar los mensajes al público objetivo. 
Surgen de esta situación los medios no convencionales, entendidos como aquellos no masivos que permiten tratar al público de una manera más individualizada y personal.

Entre ellos encontramos la publicidad en el punto de venta, más genéricamente llamada PLV, que este año 2008 ha visto incrementada su inversión en un 20,6\% (base 2007 Informe InfoAdex) siendo el medio no convencional que más ha crecido. Aun así, se reconoce entre los profesionales una tendencia general poco innovadora en este campo quedando, de esta forma, atrasado respecto al desarrollo de otras técnicas de publicidad.

Un consumidor cada vez más informado, selectivo y con mayor posibilidad de elección por la gran amplitud de ofertas, obliga a las marcas a desarrollar acciones que creen una relación y un impacto directo sobre los mismos.

La publicidad en el punto de venta basa su eficacia en la compra por impulso. Estudios realizados por POPAI aseguran que un 55\% de las compras no son planeadas (datos publicados por POPAl 2007, The Global Association for the Marketing at Retail) (Promueve № 2: 35).

Este campo no ha visto desarrollado todo su potencial ya que queda eclipsado por medios cuya eficacia y repercusión son más sencillas de medir. Esto trasciende en el hecho de que incluso los propios profesionales no saben determinar con claridad lo que engloba la PLV (técnicas) y los beneficios que ésta puede reportar a la marca.

Es por ello que este trabajo irá dirigido a crear un marco conceptual en el que describir la PLV actual, a la vez que se estudian las acciones que las marcas están desarrollando y el grado de innovación del sector, del que mucho se habla, pero poco se sabe con certeza. 


\section{Marco teórico}

\subsection{La publicidad no convencional o below the line}

\subsubsection{La BTL}

Los medios no convencionales son conocidos genéricamente como below the line 0 BTL. Es aquel conjunto de medios que permiten llegar a los consumidores de una manera más directa y personalizada, no entendidos como "masivos", y que transmiten un mensaje comercial con el objetivo de fomentar en el público una opinión favorable acerca del producto, idea u organización (Control № 530: 64) .

Este tipo de publicidad ha permitido a los profesionales poder personalizar el mensaje para que de esta forma sea más efectiva. Es por ello que la BTL, cuyo motor es la estrategia de marca, se cuenta como la forma más efectiva y eficiente de comunicar.

La publicidad no convencional se basa en un conjunto de mensajes que construyen la imagen de marca a medida que se desarrollan las acciones. Es por ello que deben estar cargadas de valor corporativo y propio para el consumidor. El esfuerzo que hacen las marcas para diferenciarse en este escenario está en crecimiento, pues cada vez son menos las posibilidades de innovación.

Así pues, los profesionales de las agencias están desarrollando herramientas que lleven el impacto del mensaje al momento en el que el consumidor debe tomar la decisión de compra, la cual, como veremos más tarde, se produce en un $70 \%$ delante del lineal (Promueve № 21:43).

En la actualidad la saturación publicitaria ha alejado emocionalmente a los consumidores de la publicidad más convencional, principalmente del medio 
televisión, aunque como norma general, la tan de moda BTL, se conjuga con la ATL con el objetivo de maximizar y optimizar los impactos.

\subsubsection{Clasificación $y$ características de medios no convencionales}

Los medios no convencionales son:

$$
\begin{aligned}
& \text { - Marketing directo } \\
& \text { - Marketing telefónico } \\
& \text { - Marketing social } \\
& \text { - Marketing móvil } \\
& \text { - Marketing personalizado } \\
& \text { - Mailing personalizado } \\
& \text { - Marketing show } \\
& \text { - Street show } \\
& \text { - Marketing promocional } \\
& \text { - PLV } \\
& \text { - Merchandising } \\
& \text { - Señalización }
\end{aligned}
$$

\begin{tabular}{|lll|}
\hline - & Animación en el punto de venta & \\
- & Tarjetas de fidelización \\
- & Regalos publicitarios & \\
- & Juegos promocionales & \\
& Advergaming \\
- & Patrocinio (actos) \\
- & Mecenazgo (actos) \\
- & RSC \\
- & Ferias y exposiciones (eventos) \\
- & Anuarios, guías, catálogos y \\
& directorios \\
- & Publicaciones de empresas: folletos, \\
\hline
\end{tabular}

Datos Obtenidos de InfoAdex ${ }^{1}$

No entra en esta investigación nombrar las características de los medios convencionales como la televisión o la radio, largamente investigados, pero sí cabe resaltar algunos de los beneficios más importantes y enriquecedores para las campañas. Las acciones below the line otorgan a los profesionales algunas ventajas sobre los above the line como:

\footnotetext{
${ }^{1}$ Esta clasificación toma como base los medios no convencionales que InfoAdex clasifica en sus estudios de inversión publicitaria.
} 
- Mensurabilidad: al ser acciones localizadas y claramente segmentadas, la posibilidad de medir los resultados es más sencilla y acertada (Control № 530: $62)^{2}$.

- Capacidad de segmentación: una de las características de la BTL es que permite dirigirse a grupos de público muy concretos (Control № 530: 62) ${ }^{3}$.

- Orientación a la acción: la BTL busca impactar a su público para desarrollar sobre ellos una actitud que pretende la acción directa (Control № 530: 62) ${ }^{4}$.

- Capacidad de alcanzar una gran cantidad de impactos con bajo coste debido a la acción directa y cercana de la BTL sobre el público objetivo.

- Acciones localizadas que permiten a las marcas mantener la esencia (mensaje) de la acción hasta que la publicidad llega al consumidor. Esto se debe a que la BTL no es una publicidad masificada, por lo que no pierde la fuerza y potencial inicial (Anuario Promueve 2006: 37$)^{5}$.

- Personalización del mensaje: la segmentación permite que cada mensaje emitido por una marca esté estructurado teniendo en cuenta las características del público objetivo al que se dirige.

Uno de los beneficios habituales de este tipo de acciones era el bajo coste que suponían. Con el tiempo los precios se han ido igualando al de los medios convencionales.

\subsubsection{La BTL en números}

Para hacernos una idea sobre la situación de la BTL en el mercado, analizar su posición económica es muy aclarador.

\footnotetext{
${ }^{2}$ Artículo realizado por Pablo Turletti, general manager de Karpa.

${ }^{3}$ Artículo realizado por Pablo Turletti, general manager de Karpa.

${ }^{4}$ Artículo realizado por Pablo Turletti, general manager de Karpa.

${ }^{5}$ Afirmación realizada por Erika Velasco directora de Marketing de Konopizza.
} 
En 2008 recibieron más de la mitad de la inversión publicitaria, más específicamente un $52,4 \%$, como podemos observar en la figura 1 .

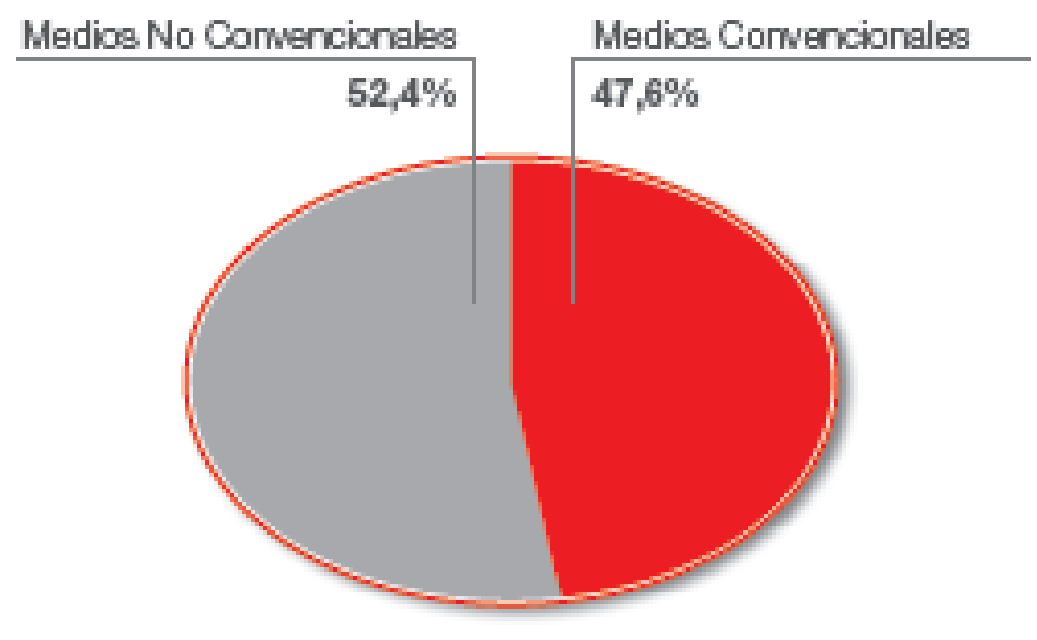

Figura 1: fuente INFOADEX 2008

En 2007, el $65 \%$ de los medios no convencionales estaba representado por cuatro categorías: mailing personalizado (1864,9 millones de euros), PLV señalización y rótulos (1275,3 millones de euros), marketing telefónico (967,7millones de euros) y buzoneo/folletos (757millones de euros) (estudio InfoAdex 2009).

Los datos más recientes proporcionados por el resumen 2009 de INFOADEX ${ }^{6}$, nos indican que la inversión en el total de medios no convencionales fue de 7.812,9 millones de euros en 2008, lo que supuso un decrecimiento respecto al año anterior del 4\% (8.136,1 millones de euros).

\footnotetext{
${ }^{6}$ Información disponible en www.infoadex.es. InfoAdex realiza el control y análisis de la publicidad (ADEX) en España. Durante los 365 días del año, controla, archiva y analiza todas y cada una de las inserciones publicitarias realizadas en todos los medios convencionales: Cine, Diarios, Exterior, Internet, Radio, Revistas, Dominicales, y Televisión.
} 
Desde 2003 los medios BTL han registrado mayores cuotas de inversión que los medios convencionales entre los que se encuentra la televisión, el gran medio publicitario por excelencia. Así ha sido la evolución ${ }^{7}$ :

\begin{tabular}{|l|c|c|c|c|c|c|}
\hline & $\mathbf{2 0 0 8}$ & $\mathbf{2 0 0 7}$ & $\mathbf{2 0 0 6}$ & $\mathbf{2 0 0 5}$ & $\mathbf{2 0 0 4}$ & $\mathbf{2 0 0 3}$ \\
\hline $\begin{array}{l}\text { Medios } \\
\text { convencionales }\end{array}$ & $7.102,5$ & $7.985,1$ & $7.306,9$ & $6.720,7$ & $6.177,8$ & $5.602,6$ \\
\hline $\begin{array}{l}\text { Medios no } \\
\text { convencionales }\end{array}$ & $7.812,9$ & $8.136,1$ & $7.447,2$ & $7.064,8$ & $6.693,6$ & $6.444,4$ \\
\hline
\end{tabular}

Figura 2: Datos de INFOADEX

Como podemos observar en la gráfica inferior, los medios que encabezan la clasificación son el mailing personalizado con 1.974,4 millones de euros, la PLV (merchandising, señalización y rótulos) con 1.548,8 millones de euros y en tercer lugar el marketing telefónico con 1.100,6 millones de euros. El resto de medios no superan los 1.000 millones de euros en ningún caso.

La necesidad de llegar de forma más directa al consumidor está desarrollando unas tendencias que se aplican cada vez más en todas las modalidades de BTL.

A pesar de ello, podemos observar que tanto la inversión en medios no convencionales como la inversión general, han disminuido a un ritmo continuo. La dinámica en el primero de los casos es menos notable que las cantidades que podemos observar en términos absolutos.

\footnotetext{
${ }^{7}$ Para ver la evolución de forma gráfica, acudir a Anexos punto seis.
} 
Esto nos indica que los medios convencionales sufren una caída más importante. Puede deberse a diversos motivos como la saturación que sufren los consumidores a través de estos canales.

Sin embargo, hay medios específicos como el mailing personalizado, el marketing telefónico, el buzoneo, marketing móvil, el PLV o los actos de mecenazgo (marketing social, patrocinio...) que al contrario que las cifras generales, aumentan, lo que nos indica la buena salud del sector a pesar de la actual situación de crisis. Podemos ver los datos en la tabla inferior.

\begin{tabular}{|c|c|c|c|c|c|c|c|}
\hline MEDIOS NO CONVENCIONALES & 2008 & $\begin{array}{l}\% \text { Inc. } \\
08 / 07\end{array}$ & 2007 & 2006 & 2005 & 2004 & 2003 \\
\hline Mailing Personalizado & $1.976,4$ & 1,9 & $1.939,5$ & $1.864,9$ & $1.776,1$ & $1.734,5$ & $1.700,5$ \\
\hline Buzoneo/Folletos & 852,6 & 3,5 & 823,6 & 757,0 & 729,2 & 744,1 & 752,4 \\
\hline Marketing Telefónico & $1.100,6$ & 4,0 & $1.058,6$ & 967,7 & 897,6 & 832,0 & 763,6 \\
\hline $\begin{array}{l}\text { Marketing Móvil (excluido } \\
\text { Intemet) }\end{array}$ & 19,1 & 62,9 & 11,7 & 6,5 & & & \\
\hline Regabs Publicitanios & 227,0 & $-41,5$ & 388,0 & 373,8 & 367,1 & 365,2 & 361,6 \\
\hline $\begin{array}{l}\text { P.L.V., Merchandising, } \\
\text { Señalización y Rótulos }\end{array}$ & $1.548,8$ & 0,7 & $1.538,0$ & $1.275,3$ & $1.225,9$ & $1.086,1$ & $1.048,1$ \\
\hline Ferias y Exposiciones & 109,0 & $-46,7$ & 200,7 & 174,7 & 150,4 & 142,1 & 130,8 \\
\hline $\begin{array}{l}\text { Actos de Patroc., Mecenaz., } \\
\text { Mark. Social y R.S.C. }\end{array}$ & 569,5 & 15,0 & 495,1 & 438,9 & 401,5 & 348,4 & 324,7 \\
\hline Actos de Patrocinio Deportivo & 457,6 & $-26,6$ & 623,4 & 560,6 & 493,0 & 470,5 & 442,6 \\
\hline $\begin{array}{l}\text { Public. de Empresas:Revistas, } \\
\text { Boletines, Memorias }\end{array}$ & 32,5 & $-39,0$ & 53,3 & 60,3 & 59,4 & 56,6 & 56,7 \\
\hline Anuarios, Guias y Drectorios & 609,9 & $-4,5$ & 638,6 & 604,2 & 589,0 & 553,7 & 511,3 \\
\hline Catálogos & 144,1 & $-25,6$ & 193,7 & 209,0 & 241,5 & 225,2 & 217,7 \\
\hline Juegos Promocionales & 50,3 & $-10,0$ & 56,9 & 48,6 & 38,2 & 36,2 & 39,1 \\
\hline Tarjetas de Fidelización & 48,1 & 4,8 & 45,9 & 40,0 & 34,8 & 32,4 & 32,6 \\
\hline Animación Punto de Venta & 67,5 & $-3,5$ & 69,9 & 65,8 & 71,0 & 66,7 & 62,7 \\
\hline SUBTOTAL MEDЮS NO CONVENCIONALES & $7.812,9$ & $-4,0$ & $8.136,1$ & $7.447,2$ & $7.064,8$ & $6.693,6$ & $6.444,4$ \\
\hline GRAN TOTAL & $14.915,3$ & $-7,5$ & $16.121,3$ & $14.754,1$ & $13.785,5$ & $12.871,4$ & $12.047,0$ \\
\hline
\end{tabular}

(") Se incluyen revistas de: Beleza, Decoración, Femeninas, Inf. General, Masculinas, Moda y Corazón.

Figura 3: Datos de INFOADEX

\subsubsection{Tendencias de la BTL}

Las últimas tendencias en acciones below the line nos señalan la actual segmentación del mercado propiciada por la creciente complejidad de la sociedad. Las formas de comunicar se deben adaptar a estas circunstancias que obligan a las 
empresas a personalizar sus mensajes y productos para responder a las necesidades de cada nicho de mercado.

Es por ello que la especialización por target (Control № 551: 68) ha adquirido una importancia vital a la hora de potenciar la eficacia de las acciones, tanto publicitarias como de marketing -tomando ambas disciplinas como diferentes-. En la misma línea se encuentra la microsegmentación (Promueve № 29: 18).

Debido a la creciente competencia y normalización de los sistemas below the line, la creatividad se ha vuelto imprescindible a la hora de lograr la diferenciación de producto o marca. Como ejemplo de esta tendencia se pueden nombrar dos nuevas disciplinas, los Cool-hunters ${ }^{8}$ y el Advergaming $^{9}$.

"Agencias y anunciantes ponen cada vez más en práctica dentro de sus estrategias las campañas 360”" (Promueve № 28:33) ${ }^{10}$, es decir, la combinación de acciones below the line con above the line. Esta acción da lugar a lo que se llama, una estrategia integrada.

Una de las partes más importante en este proceso es investigar al público objetivo y los canales más adecuados para llegar a ellos. Los últimos años dictaminan que la mejor estrategia para el éxito de las campañas es utilizar acciones BTL y ATL conjuntamente.

\footnotetext{
${ }^{8}$ Cazadores de lo "cool" o "guay". Generalmente son freelance que se dedican a predecir e identificar las tendencias, la moda 0 a la gente de éxito. La tendencia a solicitar servicio de estas personas es creciente.

${ }^{9}$ Es una nueva técnica de marketing que presenta los productos o servicios a través de juegos, ya sean de ordenador 0 clásicos.

10 Afirmación realizada por Luis Antonio Ruiz, director de marketing de Ford en un artículo de Ana Rueda.
} 


\subsection{Marketing}

\subsubsection{Definición}

Vamos a realizar una aproximación al ámbito del Marketing por ser necesario para comprender el entorno de la PLV.

Santesmases (2007:68) define el Marketing como un

"'modo de concebir y ejecutar la relación de intercambio, con la finalidad de que sea satisfactoria para las partes que intervienen y a la sociedad, mediante el desarrollo, valoración, distribución y promoción, por una de las partes, de los bienes, servicios o ideas que la otra parte necesita ".

Por otra parte, para la American Marketing Association (A.M.A.), el marketing 'es una función de la organización y un conjunto de procesos para crear, comunicar y entregar valor a los clientes, y para manejar las relaciones con estos últimos, de manera que beneficien a toda la organización (... $)^{11}$. La definición contempla el marketing como una actividad, poniendo énfasis en las relaciones con los clientes.

En ambas definiciones, y en la mayoría de las mismas, se describe marketing como una disciplina orientada a la identificación y satisfacción de los deseos y necesidades de los consumidores. Algunos profesionales apuntan que esos deseos son generados en gran medida por el marketing, que a través de diversas herramientas llega a la mente del consumidor.

\footnotetext{
${ }^{11}$ Definición obtenida de Dictionary of Marketing Terms A.M.A. disponible en www.marketingpower.com [Consultada en línea en abril de 2009].
} 


\subsubsection{Evolución del marketing}

El auge del marketing en los años 60' con el modelo de Jerry McCarthy, las "cuatro $P^{\prime \prime}$, describía una disciplina masiva que no tenía en cuenta al cliente (producto, precio, distribución y promoción). Tomando como referencia los estudios de Tellis, la lucha en esa década y las posteriores pasaba por desarrollar la mejor estrategia de producto global (2002:140).

Tellis afirma que debido al aumento de la competencia en la década de los 90', el mercado se inclinó hacia el marketing de segmentos (2002:140), es decir, las organizaciones desarrollaban ofertas y estrategias diferenciadas teniendo en cuenta los diferentes grupos de consumidores, que se establecían por sus características (hábitos, poder adquisitivo, necesidades...).

Este hecho se ha potenciado aún más entrado el nuevo milenio, que ha llevado a las empresas a desarrollar el micromarketing (Anuario 2006: 57). Esta tendencia tiene en cuenta como elemento principal al consumidor desde una perspectiva de comprador individual. Ahora se venden productos especializados a pequeños segmentos determinados por criterios geodemográficos ${ }^{12}$.

El mercado se ha convertido en un escenario muy complejo, si ya no lo era, debido a los nichos de mercado, la ya citada creciente competencia y la gran cantidad de fuentes de información a la que tienen acceso los consumidores, lo cual los hace más selectivos y predeterminados a la hora de realizar la compra.

Es por ello que el marketing actual se orienta a las relaciones one-to-one que permiten establecer una relación más directa entre consumidor y anunciante determinando un impacto más efectivo.

\footnotetext{
12 Es una herramienta SIG (Sistema de Información Geográfica) que combina variables del marketing con variables sociodemográficas en áreas concretas para determinar nichos de mercado de una forma más precisa.
} 
Ésto nos ha llevado al llamado marketing at retail que define las acciones que se realizan en el punto de venta, tanto PLV como packaging o merchandising. Es un término de reciente aplicación que responde a la creciente partida presupuestaria que los anunciantes están destinando a este tipo de acciones.

\subsection{Publicidad en el Punto de Venta o PLV}

\subsection{1 ¿Qué es la PLV?}

La definición de este concepto ha estado marcada por el escaso acuerdo entre profesionales sobre el ámbito que abarca. Si tomamos como referencia los numerosos libros que se han escrito sobre publicidad y marketing, probablemente en ambas materias se hable sobre PLV.

POPAl ${ }^{13}$ y Graphispack Asociación ${ }^{14}$ la definen como una "técnica del marketing (...) cuyo objetivo es llamar la atención sobre los detalles o características del producto (...) que otorgan un valor añadido al mismo sobre el resto de productos promocionados en el sitio en el que se puede comprar "15.

Mahave (2003:10) afirma que a pesar de ser en el punto de venta donde el consumidor toma la mayor parte de decisiones de compra, la PLV continúa siendo la gran desconocida aunque la venta impersonal, las grandes superficies comerciales y la alta competencia por la gran variedad de productos, han proliferado el uso de la misma.

Anteriormente, la venta personal era la técnica de negocio más utilizada, al igual que las tiendas eran más pequeñas y no contaban con tanta diversidad de productos y

\footnotetext{
${ }^{13}$ Para más información sobre esta organización mirar Anexos punto uno.

${ }^{14}$ La Asociación Española de Suministradores para la Industria Gráfica, Embalaje y P.L.V.

${ }^{15}$ Documental 'El poder de la publicidad en el punto de venta' [Consultado en línea en abril de 2009]
} 
marcas $^{16}$. Poseían una clara tendencia a la atención al cliente personalizada en todas las fases de la compra.

La evolución de la sociedad ha llevado a un cambio en el estilo de vida que deja atrás este tipo de comercio relacional y son ahora, las grandes superficies, las entidades que más facturan en ventas.

Es por ello que los consumidores muchas veces se ven obligados a tomar decisiones de compra por su cuenta. Son en estos casos en los que la PLV puede influir para que el comprador se decida por un producto u otro.

Este tipo de acciones, por lo tanto, además de tener que llamar la atención al público, deben proporcionar la información necesaria para que tome su decisión (Anuario 2006:39).

Haciendo referencia a Loudon y Della Bitta, la PLV se podría categorizar como una acción compuesta de diversas técnicas y materiales de exhibición, que combinadas adecuadamente con medios convencionales de forma sinérgica en una estrategia de comunicación, pueden aumentar hasta en un 550\% el recuerdo de marca (1995: 301).

Principalmente, en lo que se tienen que centrar este tipo de acciones es en generar un estímulo en el consumidor. Se entiende por estímulo 'un incitamiento en el organismo (...) para obrar desencadenado por un agente físico, químico o mecánico' (R.A.E.). Es por ello que la PLV se debe encargar especialmente de estimular los sentidos de los consumidores

\subsubsection{La PLV en números}

Dentro de los medios no convencionales, la PLV se cuenta como el segundo medio de este grupo por volumen de inversión (incluye señalizaciones y rótulos) cuyo peso

\footnotetext{
${ }^{16}$ Documental 'El poder de la publicidad en el punto de venta'[Consultado en línea en abril de 2009]
} 
sobre el total es del $17,1 \%$. Ésto significa que incrementa su cifra en un 4,0\% hasta llegar a los 1.275,3 millones de euros frente los 1.225,9 millones de euros del año anterior (datos del estudio InfoAdex 2009 referido a datos del 2008).

Evidentemente, como sector dependiente del consumo y por lo tanto de la economía, el panorama actual de la PLV está inmerso en una tendencia de desaceleración que parece puede empeorar, aunque sea uno de los medios, tanto de los convencionales como de los no convencionales, que consigue aumentar sus inversiones.

Es cierto que, de alguna manera, en momentos de crisis este sector es uno de los que se encuentran en mejor situación competitiva por ser un estímulo y un potenciador para la venta además de ser una alternativa poco costosa dentro de un presupuesto de publicidad.

Una afirmación realizada por Daniel Llano -Director General de Ogilvy Action- en el 8o Congreso Nacional y 1 - Ibérico de la Publicidad en el Punto de Venta que tuvo lugar en Madrid, arrojaba luz sobre la verdadera importancia de la PLV. Y es que los retalis de los centros de alimentación cuentan con visitas de más de 9 millones de personas, lo que supera la audiencia de los programas más exitosos en prime time ${ }^{17}$.

Es por ello que el Director General de Ogilvy Action llamaba a las agencias a tomar conciencia sobre la importancia de la PLV en el marketing ${ }^{18}$.

\subsubsection{Los límites de la PLV en el marketing at retail}

Muchos profesionales sitúan la publicidad en el punto de venta dentro del marketing. Y así sería si analizamos esta técnica desde el punto de vista de la teoría de Jerry McCarthy, denominada las $<<4 \mathrm{P}$ 's $>>$ : product, price, place, promotion.

\footnotetext{
${ }^{17}$ Reportaje sobre el 8o Congreso Nacional de Publicidad en el Punto de Venta [Consultado en línea en abril de 2009].

${ }^{18}$ Reportaje sobre el 80 Congreso Nacional de Publicidad en el Punto de Venta. [Consultado en línea en abril de 2009]
} 
La PLV se encontraría dentro de la "P" de promoción o promotion. Este "ABC" del marketing, incluye la publicidad como un instrumento 0 herramienta para el desarrollo de su actividad.

El marketing en el punto de venta (marketing at retail) engloba una serie de técnicas que ayudan a los anunciantes a llamar la atención del público en el mismo lugar de compra. Existen muchos libros en los se incluye alguna de estas técnicas dentro de la PLV, sin embargo, se diferencian por sus herramientas y por su propia naturaleza.

Principalmente se confunde con el merchandising y el packaging. Apuntemos algo sobre ambos conceptos para mayor claridad:

- Merchandising. es un concepto difícil de definir debido a lo numeroso de sus acepciones. En general, esta técnica del marketing se ocupa del la gestión del lineal, es decir, de la disposición visual de los materiales y productos en los puntos de venta con el objetivo de captar la atención de los consumidores. Dentro de esta categoría se está dando una actividad en alza con apenas una década de vigencia llamada category management. Se basa en la gestión de las diferentes categorías de productos en los retailers como unidades de negocio particulares ${ }^{19}$.

- Packaging. esta técnica se puede considerar una herramienta de la PLV. Reporta más beneficio y eficacia a la misma y es tan importante porque es la que más perdura en la mano del consumidor ya que ve el packaging hasta que consume el producto o incluso más tiempo. Es por ello que esta fase de la estrategia integrada de marketing debe ser coherente con la marca y debe ser definitiva en valores y metas ${ }^{20}$.

\footnotetext{
${ }^{19}$ Artículo publicado el 4 de agosto de 2008 en Infobrand.com Autor: Pablo Badía. Véase www.infobrand.com [Consultado en línea en marzo de 2009].

${ }^{20}$ Reportaje sobre el 80 Congreso Nacional de Publicidad en el Punto de Venta [Consultado en línea en abril de 2009].
} 
Por tanto, podemos ver que la naturaleza del merchandising es la gestión del producto en el retail y la del packaging dotar al producto de una funda exterior que sea atractiva para el consumidor. Concluimos pues, que son por naturaleza, distintas a la PLV.

Todas las herramientas que a continuación se apuntan, son globalizadas en el concepto "comunicación integrada de marketing" o $\mathrm{CIM}$ (pero en ningún caso se encuentran dentro de la definición de PLV como muchas veces se afirma):

- Promoción: Loudon y Della la definen como una actividad específica de la comunicación de marketing que ofrece incentivos adicionales (dinero, premios, regalos, productos extra, etc...) al consumidor teniendo como objetivo acelerar el proceso de venta (1995:696). Un informe realizado por Nielsen ${ }^{21}$ en 2007 afirmaba que las promociones en el canal de venta se llevan el $60 \%$ del presupuesto de promoción de los fabricantes. Así mismo apunta que las reducciones de precios temporales y las ofertas limitadas son el tipo más común de esta técnica.

- Street marketing. disciplina del marketing que engloba las acciones comunicativas que se realizan 'en directo' en el exterior. Los consumidores no han recibido una invitación previa, por lo que la sorpresa es una característica de esta técnica. Son acciones generalmente puntuales. El marketing show responde a las mismas características, pero se realiza generalmente en el interior de los comercios para presentar algún producto o servicio acompañado de actividades recreativas $^{22}$.

\footnotetext{
${ }^{21}$ Nielsen, fundada en 1932 por A.C. Nielsen, es la empresa líder en servicios de información e investigación de mercados, sistemas y herramientas de análisis.

${ }^{22}$ Véase www.marketingdirecto.com [Consultada en línea en abril de 2009].
} 
- Field marketing. este tipo de acciones recogen las actividades basadas en el cara a cara y en la relación directa con el consumidor al que se le intenta presionar para la compra en los últimos momentos de la misma. Es una técnica del marketing que aunque se realiza en el interior de los comercios, no se puede considerar PLV'23.

Como hemos visto, la PLV es una acción que puede incluir diversas técnicas para potenciar su efectividad. Todas estas acciones que se han definido son canales directos a los sentidos del consumidor con un fin persuasivo que busca la optimización de la percepción del cliente.

Podemos apuntar tras esta reflexión, que la publicidad en el punto de venta se encuentra dentro del marketing. Como publicidad se entendería el propio elemento de exhibición, pero la acción que compone una estrategia, es marketing.

Hay que realizar un apunte, y es que aunque los informes apunten a la promoción como la técnica más utilizada por parte de los fabricantes, los datos indican que la publicidad en el punto de venta genera más impacto en las ventas ${ }^{24}$ ya que aumentan en un $86 \%$ el promedio de las ventas.

Más específicamente la publicidad en los comercios ( $11 \%$ del presupuesto) genera un margen unitario de un $145 \%$ y los displays en las góndolas ( $7 \%$ del presupuesto) que aumentan las ventas un promedio de $118 \%$ (datos obtenidos del informe Nielsen).

Por lo tanto, podemos afirmar que la acción más efectiva es, una vez más, la CIM combinando PLV (incluyendo los displays) con la promoción. Genera un aumento en las ventas del $316 \%$ (datos obtenidos del informe Nielsen) ya que la oferta es lo que termina de convencer al cliente (Promueve 27:40).

\footnotetext{
${ }^{23}$ Véase www.marketingdirecto.com [Consultada en línea en abril de 2009].

24 Informe Nielsen
} 
Aún teniendo en la mano estos datos, esta combinación de técnicas representa menos del $5 \%$ de las acciones de los fabricantes ${ }^{25}$. Lo que muestra su escaso desarrollo.

\subsubsection{La PLV desde el Neuromarketing ${ }^{26}$}

Esta perspectiva de la PLV es esencial para entender la importancia de este tipo de acciones que basan su efectividad en la psicología de los consumidores principalmente en el subconsciente- y es que, como ya se ha afirmado, la mayoría de las decisiones de compra se toman en el punto de venta.

Cuando la PLV consigue en primera instancia captar la atención del consumidor, Pablo Badía (2008) en su artículo "El punto de venta en la mira" afirma que se da un "gap" de unos segundos en el que el individuo sólo tiene en cuenta sus sentidos e intuición. Es en este momento en el que la publicidad en el punto de venta tiene que ser definitiva.

En definitiva, incorpora la acción directa a los sentidos en el punto de venta buscando la optimización en la percepción del cliente a través de los estímulos.

"En el proceso de compra podemos distinguir dos aspectos que deben definir una estrategia en el punto de venta: el utilitarista y el hedonista". El primero de ellos se refiere al comportamiento racional de la compra, generalmente asociado a bienes de

\footnotetext{
25 Datos obtenidos del Informe Nielsen.

${ }^{26}$ Neuromarketing: 'Disciplina moderna, producto de la convergencia de las neurociencias y el marketing cuya finalidad es incorporar los conocimientos sobre los procesos cerebrales para mejorar la eficacia de cada una de las acciones que determinan la relación de una organización con sus clientes en todo su campo de acción: comunicaciones, producto, precios, branding, posicionamiento, targeting, planificación estratégica, canales de marketing e indagación de todos los factores que determinan el comportamiento de compra y consumo en segmentos específicos del mercado y en el cliente.' (Braidot 2005:9).
} 
primera necesidad. $Y$ en segundo lugar se distingue la parte subjetiva de la compra con el potencial de placer que se deriva de la experiencia de comprar (Basile) ${ }^{27}$.

Es por ello que una PLV debe tener en cuenta ambos aspectos y crear una sinergia entre la labor informativa y la persuasiva para lograr la mayor afectividad, generando una experiencia de compra positiva para el consumidor.

Desde este punto de vista podríamos definir la PLV como un "gestor de experiencias" ${ }^{28}$ que a través de distintos elementos materiales, tangibles e intangibles, genera una serie de estímulos creando una interacción con el consumidor que favorece y enriquece la experiencia de compra.

Braidot afirma que el Neuromarketing habla de algunos factores que influyen para generar una PLV atractiva, es decir, un "ambiente de producto" atractivo. Por ejemplo la música, los colores, la arquitectura, el diseño, la ubicación espacial, exhibidores y góndolas incluso la temperatura, el olor y el orden (2005:610).

Además añade que la ubicación de la PLV, con todos los elementos que implica, debe ser minuciosamente estudiada para impactar en la percepción visual del consumidor y atraer su atención (preferentemente en puntos calientes ${ }^{29}$ ) (2005:610). En este aspecto la publicidad en el punto de venta es sumamente importante ya que el Neuromarketing afirma que dos tercios de los estímulos llegan al cerebro a través del sistema visual (2005:609).

La PLV y en general las acciones en el punto de venta, tienen como objetivo hacer de la compra de necesidad una acción de placer.

\footnotetext{
${ }^{27}$ Artículo en www.infobrand.com.ar/notas/10348-El-punto-de-venta-como-un-merchandising-de-experiencias.

${ }^{28}$ Documental 'El poder de la publicidad en el punto de venta' [Consultado en línea en abril de 2009].

${ }^{29}$ Puntos calientes: minizonas donde la venta de los artículos es superior a la media del sector que puede ser naturales y artificiales.
} 
En su libro "Neuromarketing: Neuroeconomía y negocios", Braidot afirma que desde el punto de vista psicológico, este tipo de compras satisface los deseos ubicados en los estratos altos de la pirámide de Maslow y están asociados a pensamientos "metaconscientes" (2005:612). Es por ello que "la creatividad aplicada a los escenarios del punto de venta hacen que el principio de placer domine sobre el de la realidad" "(2005:612). Ésta es la razón por la que gran parte de las decisiones de compra son impulsivas ${ }^{30}$ y se toman en los comercios, como muestran numerosos estudios ${ }^{31}$.

La fidelización se produce cuando la experiencia del consumidor ha sido positiva. En este caso, todos los estímulos que ha recibido son acumulados en lo que se llama "acervo cognitivo" y también en su memoria emocional (2005:613).

\subsubsection{El impacto de la PLV}

Debido a todo lo apuntado por el Neuromarketing y los datos sobre la cantidad de decisiones que se toman en el punto de venta, la PLV se convierte en un elemento imprescindible si queremos aumentar el número de ventas.

Según datos publicados por POPAI, más del $70 \%$ de las decisiones de compra se toman en el punto de venta y entre un $55 \%$ y un $60 \%$ de las compras no son planeadas (Promueve 21:35). Han sido muchas las investigaciones que han estudiado el impacto que la PLV tiene en este proceso $y$, aunque los porcentajes no son algo definitivo ni exacto, todos coinciden en el alto grado de influencia de este tipo de acciones.

\footnotetext{
30 En este caso se dice que han actuado los impulsos emocionales del sistema límbico.

31 Según Loudon y Della Bitta (1995) existen cuatro tipos de compra por impulso: impulso puro; impulso sugestivo; impulso recordatorio; impulso planificado. En todas ellas, la PLV posee un papel indispensable.
} 
André Robles, consejero delegado de Dot One España, resume lo que es la publicidad en el punto de venta en dos palabras: 'impacto y beneficio inmediato' (Anuario 2006:58). Pero actualmente la PLV va más allá y no sólo tenemos que hablar de ella como un último empujón hacia la compra, sino que se constituye como un elemento de conocimiento del cliente y un canal a través del cual el anunciante puede establecer una relación con el consumidor.

Arens afirma que se ha transformado en un elemento corporativo coherente con la marca que ayuda a crear una imagen de producto $y$, en general, corporativa estableciendo un posicionamiento que consiga diferenciarlo del resto de competidores, ya que se estima que seis de cada diez compradores recuerdan algún tipo de PLV (2000: 215).

Esto lo deben aprovechar los anunciantes y agencias para utilizar la PLV como algo más que un elemento que facilite la decisión de compra y genere una compra compulsiva. De esta idea surge la PLV interactiva de la que mucho se habla, pero sin embargo, poco se ve en los puntos de venta (Control 542: 64).

La empresa POPAl desveló en 2008 que los displays dinámicos que emplean pantallas digitales incrementan las ventas un $83 \%$ frente al 39\% de los estáticos. Tampoco es necesario un desembolso de este tipo y es que los stoppers ${ }^{32}$ con voz, no muy extendidos, aumentan los impactos en un 70\% (Anuario 2008:31).

La solución para optimizar los resultados queda en innovar. Se verá en epígrafes posteriores la situación real y actual de la PLV en este sentido.

\footnotetext{
32 Término inglés que denomina a aquellos elementos publicitarios situados en el punto de venta, que sobresalen del lineal donde están colocados los productos a los que hace referencia. Este nuevo modelo de soporte detecta el movimiento de las personas y a través de un dispositivo habla a los mismos para llamar su atención.
} 


\section{Hipótesis}

Este marco teórico dibuja un escenario de la PLV que nos lleva a plantear las siguientes hipótesis:

1. La publicidad en el punto de venta se encuentra actualmente en una fase de estancamiento creativo.

2. Las marcas, agencias y fabricantes no aprovechan los beneficios que la PLV otorga.

\section{Objetivos}

1. La base de la investigación consiste, en primer lugar, en crear un marco teórico sobre la PLV ya que entre los profesionales no existe un acuerdo sobre las técnicas que incluye este tipo de publicidad.

2. Establecer una definición única de PLV atendiendo a sus características actuales.

3. Establecer una clasificación propia de características y clases de PLV.

4. Determinar el uso que las marcas realizan de la publicidad en el punto de venta y la importancia que le otorgan a la misma.

5. A través de toda la información obtenida, realizar un diagnóstico que nos indique la actual situación de la PLV.

\section{Metodología}

Las metodologías a utilizar son dos. En primer lugar, para realizar el marco teórico se utilizará la revisión bibliográfica. De esta forma se establece una base teórica a partir de la cual desarrollar la investigación y poder entender, a la vez que valorar, los resultados de la misma. 
La fuente bibliográfica tradicional, la biblioteca, no será la única a utilizar ya que actualmente Internet es una fuente bibliográfica muy amplia.

Para la revisión bibliográfica se tendrán en cuenta revistas; libros; artículos; entrevistas publicadas; noticias e incluso documentos sonoros. Para mostrar el impacto de la PLV se hará uso tanto de datos primarios, aquellos procedentes de encuestas o estudios, como de datos secundarios, que se refieren al cúmulo de informaciones ya recogidas o publicadas.

Por otro lado, para el cuerpo de la investigación se utilizará la observación directa y no participante para de esta forma determinar las características generales de la PLV actual y establecer una clasificación. Esta técnica cabe dentro de la

'categoría genérica de observación científica, que suele entenderse como los procedimientos en los que el investigador presencia en directo el fenómeno que estudia (...) sin manipular el contexto natural dónde tiene lugar la acción que se investiga', según define Siguán (2007:143).

Se ha elegido una muestra de grandes superficies para la investigación de campo debido a que son recintos idóneos por su amplitud para desarrollar de forma óptima soportes publicitarios ${ }^{33}$ (Control 543:62).

A continuación podemos ver los siete comercios que determinan la muestra:

\footnotetext{
33 La Gaceta de los Negocios en su edición del 17 de enero de 2008 anunciaba que dos gigantes de la distribución como son el Corte Inglés y Carrefour iba a seguir los pasos de los grandes almacenes estadounidenses Wal-Mart e iban a apostar por la publicidad con pantallas de televisión. El grupo presidido por Isidoro Álvarez preveía instalar en 2008 pantallas de televisión de 46 pulgadas, conocidas con el nombre de mupies gigantes, para promocionar productos. Carrefour por su parte preveía instalar un circuito de pantallas de ocho pulgadas en la sección de perfumería de algunas ciudades piloto.
} 


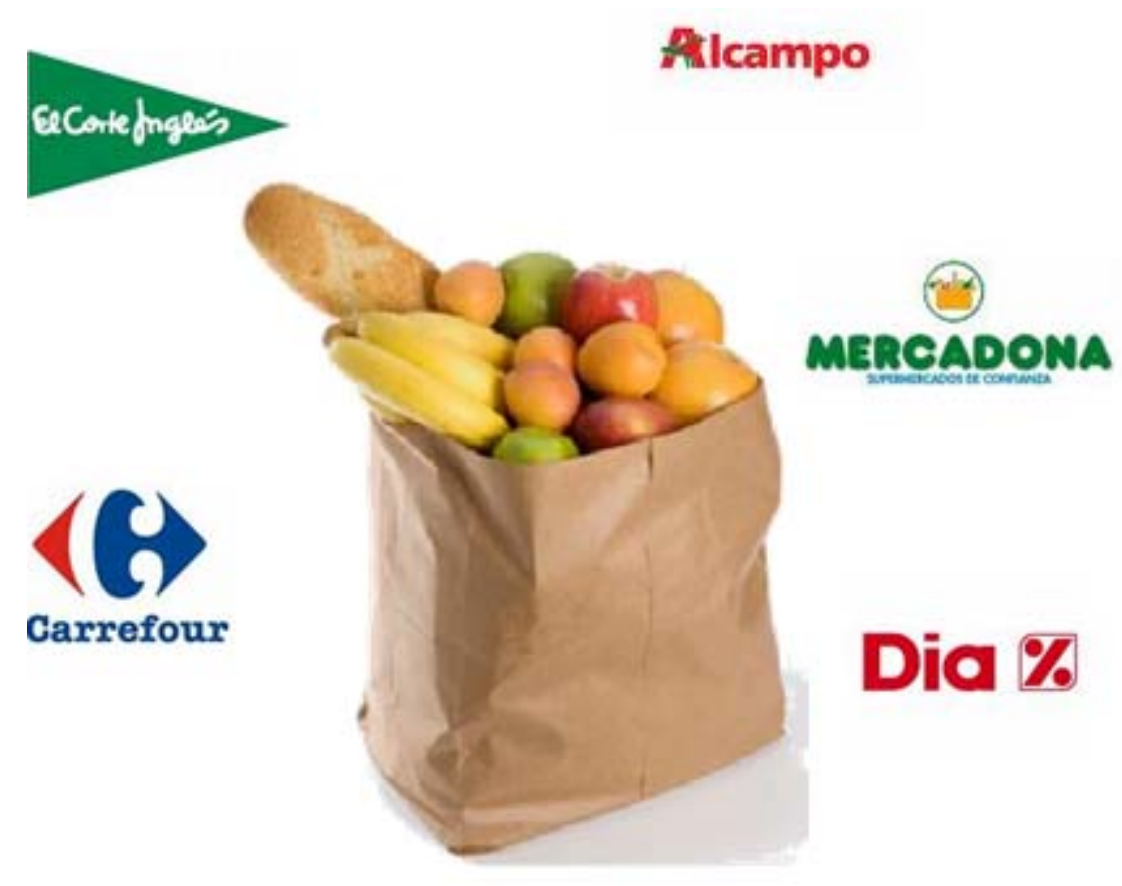

Para la decisión muestral de fechas de observación se tuvo en cuenta que en determinadas épocas la PLV se utiliza más, por lo que el objetivo era no condicionar la investigación a causa de este hecho.

Es por ello que una primera observación se realizaría en Navidades, momento de apogeo de la publicidad en el punto de venta. Además, se realizarían otras dos salidas, una en el mes de marzo y otra en el de abril. Para la correcta clasificación y decodificación de los datos recogidos, se ha establecido previamente una hoja de registro clasificatoria. 


\section{Resultados de la investigación}

\subsection{Características de la PLV}

A través de la observación y la revisión bibliográfica se han establecido una serie de características comunes de la actual publicidad en el punto de venta. Hay que apuntar que son rasgos genéricos que definen la PLV actual pero que, por diversas razones, no siempre se dan. Se han determinado teniendo en cuenta su naturaleza, objeto, y finalidad con el objetivo de realizar un retrato desde los puntos más elementales:

Naturaleza

- Técnica del marketing: la PLV se entiende como una acción estratégica componente de una determinada campaña que se planea para la consecución de unos determinados objetivos a través de publicidad en el lugar en el que los consumidores realizan las compras.

- Tipo de publicidad: los materiales que utiliza la publicidad en el punto de venta entendida como acción estratégica de marketing, son considerados publicidad: displays, cartelería, stoppers, folletos e incluso los elementos que componen la PLV digital (catálogos digitales, información, mensajes, etc...)

- Medio no convencional (below the line): se entiende también como un medio a través del cual un anunciante transmite un determinado mensaje sobre su institución, producto o servicio a los consumidores de una forma más directa y personalizada.

- Situada en el interior de un comercio: para poder ser denominada PLV, la publicidad debe estar expuesta en el mismo sitio en el que se puede realizar la compra del producto promocionado.

- Estática: este concepto hace referencia al hecho de que la publicidad en el punto de venta ha de estar constituida por algo inerte, es decir, que no puede ser 
un espectáculo o actividad recreativa (marketing show). Esto no quiere decir que no se permitan formas interactivas de comunicación.

- Estacionalidad: una de las características de la publicidad en el punto de venta es que se crea para un tiempo determinado para luego renovarla o eliminarla. Se puede deber a que se había realizado para la promoción de un nuevo lanzamiento, para algún tipo de oferta o simplemente por ser una época de alto consumo - por ejemplo Navidades- que luego decae.

- Bajo coste: una de las razones por las que la PLV posee tanta partida presupuestaria por parte de los anunciantes, es su excelente relación impactocoste. Este tipo de acciones representan para las marcas una gran cantidad de impactos de calidad con un coste y esfuerzo más bajo del que suponen los medios convencionales y muchos below the line.

- Efectividad potencial: es uno de los pocos canales y medios que no representa un tiempo indefinido entre que el consumidor recibe el impacto o mensaje y éste realiza la acción de compra - o no compra-. Esto asegura una calidad de impacto y de retención del mensaje más alta respecto al resto de acciones.

- Seducción: uno de los principales objetivos de la PLV es seducir al consumidor para que de esta forma se interese por el producto y reciba el mensaje. Para ello el material debe ser creativo y estar situado estratégicamente, lo que requiere un estudio muy cuidadoso.

- Debe estar situado en un lugar estratégico: los lugares más codiciados son los llamados puntos calientes, es decir, el lado derecho del comercio; el lugar donde se paga y las esquinas de más tránsito.

- Creatividad: permite el desarrollo de creatividad con un amplio abanico de posibilidades por el escaso desarrollo de la PLV a través de materiales, acciones, arquitectura efímera, interactividad, etc. 


\section{Objeto}

- Presenta un producto o servicio: como toda publicidad, debe promocionar un producto o servicio que debe estar a disposición del consumidor o por lo menos indicar la forma de ser adquirido.

- Herramienta informativa (en menor medida): las acciones de PLV deben ir acompañadas de una explicación al consumidor sobre el producto. La información ha de ser importante para el consumidor para evitar de esta forma la saturación (importante para su decisión de compra).

- Herramienta de promoción: generalmente las acciones de PLV las encontramos unidas a una acción promocional, es lo que se llama marketing promocional. Ya hemos visto en apartados anteriores que conjugar elementos de publicidad en el punto de venta con promociones y ofertas, aumenta las ventas en un $316 \%{ }^{34}$.

- Dirigir la compra: una buena PLV debe retener al consumidor y dirigir su compra.

- Resalta los beneficios del producto o servicio: una de sus finalidades principales es destacar los beneficios más sobresalientes del producto o servicio promocionado para llamar la atención del consumidor y aportar valor añadido al mismo.

- Llamar la atención del consumidor para de esta forma poder transmitir el mensaje.

- Crea un ambiente (propicio) para la venta: la publicidad es una forma de crear un ambiente adecuado para la compra. Los consumidores cada vez más perciben la acción de comprar como una acción lúdica más que como algo obligatorio y tedioso. Este tipo de materiales se deben encargar de hacer que los consumidores se sientan a gusto.

\footnotetext{
${ }^{34}$ Explicación en la página 14 del documento.
} 
Finalidad

- Refuerza mensajes transmitidos a través de otros medios: como ya hemos podido observar, la PLV es un medio idóneo para utilizar combinado con medios masivos para aumentar el impacto.

- Crea imagen de marca: la PLV debe considerarse como una parte activa en la construcción de imagen de marca. Es por ello que el logo debe estar siempre presente en los soportes de publicidad en el punto de venta, preferiblemente destacado. Los colores también son importantes en este sentido pues deben ser coherentes con el producto y lo que se quiere transmitir. En general se puede decir que ayuda a la creación, coherencia y fuerza de la imagen corporativa y la marca.

- Aumenta el recuerdo de marca: por ello debe ser coherente con la imagen de la misma en colores, mensaje y filosofía. El logo debe estar claramente diferenciado para un mejor recuerdo y asociación.

- Crea un posicionamiento estratégico de marca: a través de la coherencia en los mensajes emitidos, la unidad en los conceptos clave y la "corporatividad" en las acciones.

- Ayuda a diferenciar el producto o servicio del resto de la competencia: a través de las características anteriores, la PLV debe diferenciar el producto 0 servicio que promociona del resto de competencia, bien sea para crear un posicionamiento clave o para que los consumidores elijan comprar esa marca.

- Establece una relación con el cliente: en el caso de una PLV interactiva permite establecer una conexión entre consumidor y anunciante de una forma temporal e inmediata. Crea una sinergia entre el consumidor, que tiene una necesidad, y el producto, que le ofrece unos beneficios y valores añadidos. La finalidad es que esa relación sea atemporal y se prolongue en el tiempo buscando la fidelidad del cliente.

- Favorece el autoservicio: la acción de comprar, antes guiada por un vendedor, se ha convertido en lo que se llama autoservicio. Los consumidores han de 
seleccionar un producto entre varios por sí mismos sin ayuda del vendedor. Es decir, que los elementos de publicidad en el punto de venta deben aportar la información necesaria al consumidor para la elección del mismo sin que éste tenga que recurrir a otras fuentes.

- Fomenta la compra del producto: en definitiva, todo tiene que ir dirigido a crear en el cliente la necesidad y el deseo de comprar el producto o servicio ofertado.

\subsection{Definición de PLV (Promoción en el Lugar de Venta)}

A partir del marco teórico que nos ha acercado al escenario de la PLV, y de los resultados obtenidos tras la observación directa, nos atrevemos a definir la publicidad en el punto de venta como:

Técnica del marketing que se realiza en el interior de los puntos de venta con el objetivo de atraer la atención del consumidor e informarle sobre una marca, producto, servicio o idea a través de materiales gráficos, digitales y otros resaltando sus beneficios respecto a la competencia para promover su compra y crear un posicionamiento de marca estratégico.

En este debate entre si la PLV es publicidad o marketing, la mayoría de los profesionales analizados en la revisión bibliográfica, la situaban en la segunda de las disciplinas ${ }^{35}$ como podemos observar el la figura 4.

\footnotetext{
${ }^{35}$ A través de la revisión bibliográfica se han analizado diversas entrevistas realizadas a profesionales del sector y publicadas en revistas como Promueve o Control. Desde este punto se ha determinado en que ámbito - publicidad o marketing- incluían la PLV. También se ha tenido en cuenta la opinión de los autores de todos los libros utilizados para la investigación. De esta forma recogemos la opinión de los profesionales.
} 


\section{Área a la que corresponde la PLV según profesionales}
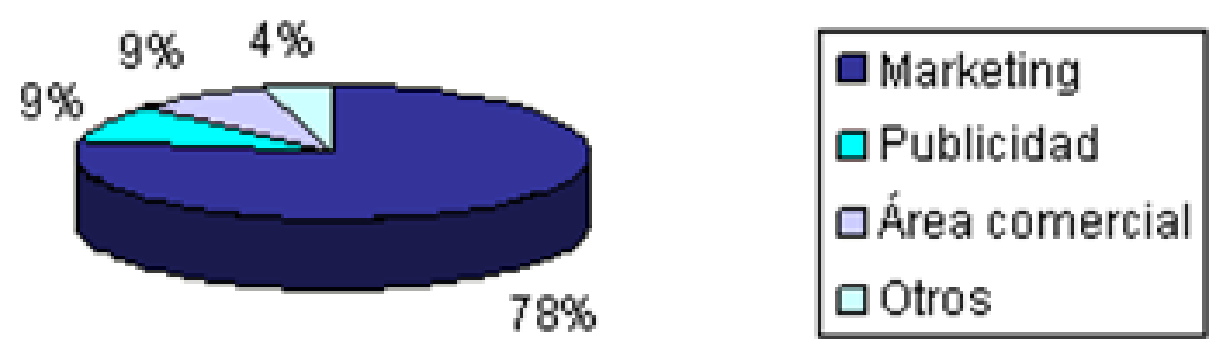

Figura 4: Elaboración propia

Sin embargo, dependiendo del punto de vista desde el que se utilice la PLV también la podemos definir:

Como Material (publicidad): conjunto de materiales y elementos propios de la publicidad que se exhiben en un determinado comercio con el objeto de seducir y llamar la atención de los consumidores para promocionar un producto o servicio de forma que éstos se interesen por su compra o por obtener más información.

Como Medio: se entiende también como un medio no convencional o below the line a través del cual un anunciante trasmite un determinado mensaje sobre su institución, producto o servicio a los consumidores de una forma más directa y personalizada en el lugar de venta a través de materiales publicitarios como displays, expositores o pantallas digitales. 


\subsection{Clasificación de las PLV}

A partir de todo lo establecido anteriormente, nos vemos es disposición de establecer una clasificación teniendo en cuenta diversos factores que condicionan las acciones de publicidad en el punto de venta.

1. Relacionando la PLV con el tiempo:

- Puntual: son aquellas que se realizan con el objeto de dar a conocer una promoción u oferta que tiene una duración determinada - menos de cuatro semanas- y que se realiza como algo extraordinario, es decir, que no entra dentro de la dinámica habitual del producto o servicio.

- Estacional: es aquella que se realiza para un periodo determinado generalmente caracterizado por unos altos índices de consumo de ese producto o servicio. Por ejemplo los juguetes en Navidades o las cremas solares en verano. Suelen tener una duración de entre tres y cuatro meses.

- Fija: es aquella que está fija en un punto de venta y que por lo tanto está fabricada con materiales menos flexibles, de mayor calidad y que mantienen sus cualidades pasado un tiempo prolongado.

2. Relacionado con los materiales:

- Fijos: son aquellos materiales que pueden soportar un largo periodo de tiempo en el punto de venta sin perder calidad. Suelen ser madera, metal y plástico. Se utilizan para acciones de más de tres meses.

- Temporales: son materiales que se utilizan para acciones de pequeña duración o de escasa escala. Son retiradas cuando se acaba el producto o las semanas marcadas por la agencia. 
3. Relacionado con su objetivo:

- De marca: el objetivo es generar recuerdo de marca o asociar un determinado producto a una firma. Para ello la PLV debe guardar una coherencia con la imagen de marca para generar corporatividad y asociación.

- De producto o servicio: su finalidad es promocionar un producto para diferenciarlo de la competencia o simplemente recordar la existencia del mismo.

- Promoción: destacar una oferta extraordinaria que aporta un valor distintivo y adicional al consumidor.

- Lanzamiento: su fin es promocionar un nuevo producto presentándolo al público y llamando la atención sobre el mismo para que se tenga conocimiento de su salida al mercado.

4. Cantidad de puntos de exposición:

- Circuito: es aquella publicidad que se establece estratégicamente en más de dos puntos de venta de diferente firma. Puede ser debido a las características del público que acude a ellos, por los beneficios que aporta el comercio a la marca o por tener una mayor notoriedad.

- Circuito interior: es aquella PLV que se ha situado en diferentes lugares dentro de un mismo punto de venta.

- $\quad$ Puntual: se elige un sólo punto de venta en el que exponer una PLV y un sólo espacio dentro del mismo.

5. Carácter:

- Expositor: en este grupo incluimos todos los elementos y expositores que sirven para mostrar el producto o servicio. 
- Señalético: no es necesario que contengan el producto y van más dirigidos a crear imagen de marca o un refuerzo de la misma. También a señalar la disposición de un determinado producto en ese centro comercial. Puede ser considerado un stopper que señala dónde está el producto o un cartel.

- Digital: este tipo de PLV se dirige a mostrar el producto de una forma más impactante a través de pantallas de televisión digitales y LCD con las que pueden proporcionar más información.

- Interactivo: PLV que invita de alguna forma al consumidor a interactuar con el producto.

6. Por sus impactos:

- Impacto simple: se utiliza un único impacto para llegar hasta los consumidores. Se realizaría a través de un único elemento de PLV situado en un único espacio.

- Impacto combinado: la estrategia determina que un mismo mensaje se emite en diversos lugares y a diferentes tiempos con materiales de PLV de diferente carácter.

- 360ㅇ: se emite un mensaje a través de diferentes medios con el objetivo de crear una predisposición y un posicionamiento que posteriormente se refuerza en el punto de venta.

7. Movilidad:

- Estático: se entiende por estático todo aquel material que no puede ser desplazado de su lugar de emplazamiento.

- Móvil: es aquel material publicitario que debido a su composición tecnológica o material puede moverse automáticamente o manualmente. 
8. Sonido:

- Sonoro: a través de tecnología digital o altavoces la PLV puede emitir sonidos o incluso aportar información a los consumidores.

- No sonoro

\subsection{Datos de las formas de PLV observadas}

El total de marcas que han utilizado algún tipo de publicidad en el punto de venta dentro de las 7 superficies observadas han sido 119. Del total de los mismos, el 13,44\% han utilizado PLV digital, de las cuales un 47,06\% daban información del producto a través de sonido, el cual lo tenían otro $47,06 \%$.

El total de PLV que permitía al público interactuar de alguna manera con el producto ha sido el 9,2\%. La publicidad en el punto de venta que sobresalía por tener una arquitectura efímera que la diferenciaba del resto corresponde al 7,56\%.

Por otro lado, las acciones que han utilizado un display para la presentación del producto, servicio o marca han sido de casi el $60 \%$. El resto correspondía a simples cartones como recipientes, cartelería, pantallas y otros.

Un $27,7 \%$ de toda la PLV eran cartones con la impresión de la marca, colores y logo. Sólo 3 de las 119 marcas utilizaban algún otro elemento que no fuera una pantalla, un display, expositor o cartelería. Estas tres marcas añadieron luz y stoppers.

Un $15,1 \%$ combinaron varios elementos de publicidad en el punto de venta mientras que el resto únicamente utilizaron uno. En su mayoría displays.

Un dato a resaltar es que 63 de las marcas recogidas en el estudio, es decir un $52,9 \%$, poseen actualmente un spot en televisión y un $24,37 \%$ tienen publicidad en 
varios puntos de venta. Además se ha podido observar que el $10 \%$ de la PLV existente en las siete superficies estudiadas ha combinado esta acción con algún tipo de promoción u oferta. Por último un $21 \%$ de las mismas estaban dirigidas a promocionar un nuevo producto.

\section{Conclusiones}

Como idea general podemos afirmar que la PLV es una técnica del marketing

En el punto 2.3.3 apuntábamos que una acción de marketing que conjugara PLV con una promoción u oferta limitada podía aumentar las ventas de un producto en más de un $300 \%$. Sin embargo, los datos recogidos tras el estudio reflejan que las marcas no aprovechan esta posibilidad, sólo un $10 \%$ de las 119 marcas que realizaban publicidad en el punto de venta.

Por el contrario, sí que se puede afirmar que un alto porcentaje de las mismas utilizan la PLV complementándola en gran medida con otros medios como la televisión, que aumenta potencialmente su efectividad.

En cuanto al elemento creativo dentro de los materiales de PLV, se puede afirmar que brilla por su ausencia. En general las acciones no destacan ni por su creatividad, ni por su diseño. Tampoco lo hacen por la variedad de elementos de PLV, ya que casi todas las marcas hacen uso de los displays, los expositores o la cartelería.

Son numerosas las razones que podríamos postular para estos resultados tan negativos. Una de ellas ha surgido en la realización de este estudio, aunque su verdadero alcance se debería demostrar en otra investigación ya que en la revisión bibliográfica nada se ha leído sobre este hecho. Se ha podido observar en los comercios que conforman la muestra, que la cantidad de publicidad corporativa y de 
los productos propios de los centros comerciales superaba con creces aquella realizada por las marcas de productos que en ellos se venden.

Esto se puede deber al auge de las marcas blancas en la actual situación de crisis económica. Los distribuidores ven en este hecho una oportunidad de aumentar su facturación, lo que crea una competencia desigual.

Contradiciendo las tendencias que apuntan los libros, artículos y entrevistas a profesionales, la PLV digital e interactiva es mínima. Como muestran los datos un 13,44 y un $9,2 \%$ respectivamente del total de las 119 marcas registradas.

Aunque es perceptible una tendencia renovadora en las marcas que les lleva a diseñar packagings más atractivos, con colores llamativos y formas más innovadoras, el terreno de la PLV sigue apenas explorado.

Las firmas de videojuegos y consolas (Play Station, X-Box o Guitar Hero) son los sectores que más destacan en el escenario de la PLV con materiales que permiten al consumidor interactuar con el producto ofrecido.

Sobre la saturación de publicidad en los puntos de venta, hay que decir que se ha escrito mucho, pero como reflejan los datos de marcas que utilizan la PLV (119), este debate está por ahora fuera de lugar. En todo caso habría que hablar de una saturación de productos o marcas que hacen que el acto de compra se convierta en una acción turbadora y pesada para los consumidores. Algo que como ya hemos comentado, la PLV debe "aliviar".

Otra de las conclusiones que se pueden extraer de este estudio es que la cantidad de PLV en una superficie es mayor cuantos más metros tienen los comercios. Centros 
como Dia, Eroski o Mercadona ${ }^{36}$ tienen un nivel de elementos de PLV mucho menor al de El Corte Inglés o Alcampo.

Este hecho nos invita a pensar que los anunciantes y agencias no determinan los lugares en los que van a implantar la PLV a través del estudio de su público más óptimo, microsegmentación o micromarketing, sino que tienen en cuenta principalmente la afluencia a estas superficies.

En general podemos determinar que la PLV es un sector poco innovador. Aunque las firmas hacen uso de estas acciones, lo valoran en su mayoría como algo complementario. Es por ello que dirigen menor atención y esfuerzo al desarrollo de una buena publicidad en los lugares de venta, aún sabiendo el impacto que éstas tienen en la decisión de compra.

Además, como ya se ha apuntado, la PLV es la última publicidad que el consumidor recibe de las marcas antes de realizar su compra.

¿No son razones suficientes para empezar a dar a la PLV la importancia que merece?

\section{Bibliografía}

ALCAIDE, J. C. "Micromarketing y Geomarketing. Definición y premisas". . Publicado en www. marketingdeservicios.com.

Disponible

en:

www.marketingdeservicios.com/articulos/micromarketing-y-geomarketing-definiciony-premisas/

ALONSO, B (2004): Animación del Punto de Venta. Ciclos Formativos Profesionales. Grado Medio Comercio y Marketing, ed. EDITEX. Madrid.

\footnotetext{
${ }^{36}$ Ver gráfica 2 en ANEXOS punto 6.
} 
ARENS, WI LLIAM F. (2000): Publicidad. Editorial McGraw Hill 7ํ edición. Madrid.

BADÍA, P. (2008): "El punto de venta en la mira". Artículo publicado en www.Infobrand.com el 4 de agosto de 2008. Disponible en: www.infobrand.com.ar/notas/10952-El-punto-de-venta-en-la-mira.

BASILE, C. (2008): "Punto de venta como un merchandising de experiencias". Artículo publicad en www.Infobrand.com el 10 de marzo de 2008.

BOLETÍN TNS News № 32

BRAIDOT, NÉSTOR P. (2005): Neuromarketing: Neuroeconomía y negocios, ed. Puerto NORTE SUR. Madrid.

HERRARA, C: "POPAI (2009): del brief al punto de vista exitoso". Artículo publicado en www.Infobrand.com el día 22 de abril de 2009. Disponible en: www.infobrand.com.ar/notas/12123-POPAl--del-brief-al-punto-de-venta-exitoso-

LOUDON, D. L. y DELLA BITTA, A. J (1995): Comportamiento del Consumidor, ed. McGraw-Hall. Madrid.

MAHAVE, A. H. (2003): "El punto de venta, clase de la victoria" en Revista MK: Marketing + ventas. ำ 18. ํㅡ 177.

MARTÍNEZ MARTÍNEZ, I. J. (2005): La comunicación en el punto de venta: estrategias de comunicación en el comercio real y on-line. Escuela Superior de Gestión Comercial y Marketing, ESIC. Madrid.

Publicación de marketing promocional y organización de eventos Promueve Anuario 2006 
Publicación de marketing promocional y organización de eventos Promueve Anuario 2007

Publicación de marketing promocional y organización de eventos Promueve Anuario 2008

Publicación Promueve № 21, 24, 27, 28, 29

Publicaciones InfoAdex

Revista Contro/ №s $527,530,533,542,543$ y 551.

RUSSEL, J. T.; CANE, W. R. y WHITEHILLKING, K. (2005): Kleppener Publicidad. 16므 edición, ed. PEARSON Educación. México.

SANTESMASES, M. (2007): Marketing: conceptos y estrategias, ed. Pirámide 5o edición. Barcelona.

SIGUÁN, M. V. (2007): Técnicas cualitativas de investigación social, ed. Síntesis Sociología. Madrid.

TELLIS, G. J. (2002): Estrategias de Publicidad y Promoción, ed. Pearson Addison Wesley. Madrid.

\section{Webgrafía}

- http://www.popai-spain.org/noticias/noticia. php?idnoticia=19

- http://www.graphispack.org/news.php 
- www.infobrand.com

- www.nielsen.com

- http://www.afexplv.com/empresa/index.php?P_langs=es

- http://www.marketingpower.com/

- www.marketingdirecto.com

- www.infoadex.es

- http://www.marketingpower.com/ (Dictionary of Marketing Terms A.M.A.)

- www.rae.es

\section{Documentos sonoros}

- Documental 'El poder de la publicidad en el punto de venta' de ADIFA-PLV, POPAI, Graphispack Asociación y Hispack. Publicado en www.youtube.com en septiembre de 2008 por Marketingdirecto.com. Disponible en: www. youtube.com/watch?v=v4zMf0B56zs.

- Reportaje sobre el 8 - Congreso Nacional de Publicidad en el Punto de Venta realizado por www.pronoticias.com y publicado en www.youtube.com en mayo del 2008. Disponible en: www.youtube.com/watch?v=v4zMf0B56zs. 


\section{Anexos}

\subsection{Un pequeño recorrido por las agencias dedicadas a la PLV $^{37}$}

Un claro dato sobre el éxito de la PLV como acción de marketing y comercial, es la proliferación de agencias dedicadas íntegramente a la creación de acciones de publicidad en el punto de venta.

En España existen 59 empresas que operan al 100\% en la actividad y el diseño de PLV. Otras 30 empresas fabrican tangencialmente PLV tridimensional, principalmente temporal. Por otro lado existen 150 empresas e imprentas que realizan displays y la cartelería habitual. También existen 6 más que fabrican extensionales de packaging a la PLV (por promociones u ofertas, agrupaciones y embalajes expositores).

En una tercera fase, hay 6 empresas que se dedican únicamente a la gestión de aspectos logísticos en el antes, durante y después de la PLV.

En la especialización de elementos informático-electrónicos, podemos contar a otras 6 organizaciones.

Estas organizaciones apostaron en sus día por un tipo de publicidad en alza y con gran potencial que buscaba el contacto directo co los consumidores para crear unos estímulos que le incitasen a la compra del producto. Una acción que se sale de lo convencional y requiere por lo tanto una creatividad y efectividad especial.

\footnotetext{
${ }^{37}$ Datos obtenidos de las publicaciones Promueve.
} 
- Dot One España: especializada en el empleo de soportes de publicidad y comunicación innovadores. Creación y gestión de canales multimedia publicitarios y corporativos. Circuitos de publicidad multimedia y estática en puntos de venta.

- AFEX PLV, S.L.: especializados en asesoramiento, diseño, fabricación, producción y distribución de PLV en un servicio integral que comprende el ciclo completo. Hay que resaltar que el $30 \%$ de su producción tienen como destino el mercado extranjero.

- Grupo Zedis: constituido en 1979, es actualmente una de las empresas más importantes en Publicidad en el Punto de Venta en el territorio Español. Ofrece servicios integrales de PLV(también para el mercado internacional) con el diseño, fabricación, implantación y mantenimiento de las acciones PLV en los comercios. Recibió un "Oscar de Oro" en 2006 por parte de POPAl European Awards y también fueron premiados en Liderpack 2007.

- Sanca Servicios Generales a la Comunicación, S.A.: en la década de los 90', esta agencia comienza a ofrecer a sus clientes un servicio integral que incluye el desarrollo de sistemas de impresión, el diseño de PLV y estructuras. Actualmente ofrecen comunicación en el exterior, comunicación visual en el interior (incluye marketing show), comunicación el punto de venta además de confecciones y montajes especiales.

- Grupo Miralles: este grupo ofrece soluciones integrales en packaging y material PLV con su conceptualización, investigación, diseño, fabricación y gestión. ${ }^{38}$

- Adaequo: pack\&PLV: empresa dedicada a la fabricación de expositores de suelo, mostradores, vitrinas y elementos de decoración además de packaging.

- Disme: fundada en 1962 ofrece diseño, fabricación, gestión y logística de expositores en el punto de venta además del desarrollo de acciones de merchandising teniendo en cuenta principalmente la imagen de marca de los clientes.

- Smart Play System: nació en 1998 como estudio de diseño gráfico especializado en soluciones de impresión digital en gran formato. Actualmente es

38 www.mirallescartonajes.es/planes/cast/01.html 
la empresa líder en publicidad dinámica con la instalación y gestión de pantallas de plasma y LCD, interactividad vía Bluetooth con móviles desde los displays, descarga de catálogos digitales interactivos, comunicación vía SMS, sistemas de contoneo de impactos de visibilidad de anuncios y otras aplicaciones.

En general, las empresas españolas dedicadas a la PLV se dividen en tres escalafones. El primero, al que pertenecen pocas compañías que facturan más de 10 millones de euros. Un segundo grupo que se cuenta entre los 10 y 6 millones de euros. Y por último, el tercero al que pertenecen la mayoría de grupos que se situaría en 3 millones de facturación.

Mención a parte merece POPAI ${ }^{39}$, The Global Association for Marketing At Retail, por ser la única asociación mundial de promotores de marcas y de cualquier acción de Publicidad en el Punto de Venta, incluida su fabricación, además de materiales de merchandising y acciones de promoción en los comercios.

El objetivo de esta Asociación que se creó en 1962 es optimizar el sector de la PLV ayudando a las empresas agrupadas bajo su organización facilitando la información necesaria para ello. POPAl Global posee delegaciones en cada país miembro y de forma corporativa emite boletines, seminarios y conferencias que ayuden a la eficiencia de sus miembros.

POPAI Spain, miembro del Board of Directors de POPAl, se convierte pues en un foro de debate que se materializa una vez al año con el Congreso anual (MadridBarcelona) en el que los profesionales del sector pueden intercambiar opiniones y conocimientos.

ADIFA-PLV, la Agrupación de fabricantes y diseñadores de PLV, está asociada con POPAl y son una fuente muy importante de estudios sobre el punto de venta.

\footnotetext{
${ }^{39}$ Point-of-Purchase Advertising International
} 
En España, como ya muestran las gráficas de inversión en PLV, esta técnica está adquiriendo cada vez más importancia por su eficacia e impacto. Claro ejemplo de esta tendencia es el Congreso Español de la PLV del que se celebró su número VIII en 2008.

\section{2. ¿Cómo se pude medir la eficacia y el impacto de la PLV?}

\section{Encuestas de recuerdo:}

Pongamos el ejemplo de la marca Kit-Kat. Realizó una PLV en varias gasolineras. A través de encuestas a la salida del los comercios, determinaron que el 66,6\% de los encuestados recordaban la publicidad, el producto anunciado y la marca. Además, un $26,1 \%$ habían adquirido el producto anunciado.

Esto supuso finalmente para Kit-Kat un aumento en las ventas de un $150 \%$ de un mes para otro (Arens 2000: 216).

\section{Informes de ventas.}

A través de la información de las ventas de antes, durante y después de la campaña de PLV. Si utilizamos estos números y los relacionamos con el efecto de la publicidad, podemos determinar la influencia que ésta ha tenido en las ventas (Anuario 2006:60).

\section{3. Última tecnología.}

De la mano de TNS que en 2007 reforzó su división internacional de investigación en el punto de venta a través de la compra de Sorensen Associates, empresa de EE.UU especializada en estudios de mercado en el punto de venta, nos llegan dos formas más de poder medir los resultados de la PLV. En primer lugar mediante el sistema tecnológico PathTracker y por otro lado el seguimiento de todo el proceso de compra 
mediante la grabación de vídeo, que sigue al consumidor desde antes de entrar al establecimiento hasta el momento en el que realiza su compra ${ }^{40}$ (TNSnews № 32:1).

Estos datos son recogidos y posteriormente analizados y plasmados en estudios de mercado.

\section{Estudios de mercado.}

Aunque es un método menos fiable por entrar en juego la participación del consumidor, esta técnica que se basa en la realización de preguntas a los mismos en diferentes momentos de su compra (mientras el individuo elige su producto, cuando ya ha realizado su compra o cuando abandona el comercio), puede arrojar numerosos datos sobre el efecto e influencia que la PLV ha provocado -recuerdo, impacto, influencia en la compra...- (Anuario 2006:61).

\section{Vocabulario ${ }^{41}$}

11.1. Display. Término inglés para denominar los soportes publicitarios utilizados para presentar algún producto o servicio de carácter fijo o móvil, estático o interactivo, de pie o colgante además de tridimensional. Los materiales con los que está fabricado pueden variar (cartón, metal, plástico, etc...).

11.2. Stopper. Término inglés que denomina a aquellos elementos publicitarios situados en el punto de venta, que sobresalen del lineal donde están colocados los productos a los que hace referencia.

11.3. Display interactivo: Denomina a los soportes publicitarios que incluyen una pantalla digital utilizados en el punto de venta para presentar un producto o servicio de carácter fijo o móvil, estático 0 interactivo, de pie o colgante además de tridimensional. Los

\footnotetext{
40 Datos obtenidos de la página web de TNS www.sofresam.com/.

${ }^{41}$ Definiciones obtenidas a través del diccionario de la página web www.marketingdirecto.com.
} 
materiales con los que está fabricado pueden variar (cartón, metal, plástico, etc...).

11.4. Góndola: Mobiliario de venta compuesto por varias estanterías sobre las que se colocan los productos al alcance de la mano del comprador, ubicado entre pasillos dentro de un autoservicio. Las características fundamentales que debe tener una buena góndola son:

11.4.1. Debe presentar los productos a la vista del comprador, siendo aconsejable que la góndola mida, a partir de unos 40 centímetros desde el suelo, una altura no superior a los 150 centímetros.

11.4.2. Su tamaño debe ser proporcional a las dimensiones del establecimiento y al volumen de ventas del mismo.

11.4.3. Debe tener un diseño llamativo y en armonía con el resto de elementos que conforman el autoservicio.

Las góndolas presentan varios niveles en función de la fuerza promocional que se quiera dar a los productos que contienen: el nivel del suelo, el nivel de las manos y el nivel de los ojos. Es este último el más importante debido a su mayor visibilidad para el comprador.

- Cabecera de góndola: se considera un emplazamiento privilegiado al exhibir sus contenidos de forma preferencial y en zonas de tráfico cruzado

- Colgante: Panel publicitario impreso por ambas caras realizado en cualquier material, generalmente cartón o plástico, destinado a ser colgado en el techo de un establecimiento. 
- Stand: construcción prefabricada que se utiliza para exponer productos o servicios como parte de una acción comunicativa temporal realizado por diversos materiales véase cartón, madera, metal, plástico, etc...

- In-Store TV: acción de publicidad en el punto de venta en la que se sitúan televisiones o circuitos de las mismas para promocionar un producto o servicio.

- Arquitectura efímera: arte gráfico que trata de diseñar, crear, proyectar espacios efímeros, tales como stands, quioscos o estructuras desmontables.

\section{Listado de las marcas que componen los resultados}

- Barbie

- Barco Pirata

- Bayer-Garden

- Colacao

- Delaviuda

- Dream Works

- Duracell

- EA Sports

- Energicar

- Feber-Famosa

- Ferrero Rocher

- 5

- Flex

- Guitar Heroe

- Hankock

- High School Musical
- Huesitos

- Kalia Vanish

- Kandoo

- Kellog's

- Lego

- LG

- Mi Life

- Monopoli

- Movistar

- Nancy

- Nenuco

- Nenuco

- Nestle

- Nivea

- Orbit

- Pedigree
- Philips

- Pikolin

- Pixel Xips

- Play Station

- PlaySkool

- Samsung

- Sanex

- Scotch-Brite

- Sharp

- Shuss

- Simba Disney

- Transformers

- Trident

- Vitalínea

- Wanted

\section{Resultados completos}

- PLV+Promoción: $10 \%$

- PLV Digital (pantalla) $14,3 \%$

- Con sonido $7,56 \%$

- Daban información 47,06\% 
- Interactivas: 9,2\%

- Display+ producto: $59,57 \%$

- Display o expositor: $7,56 \%$

- Arquitectura efímera: 7,56\%

- Cartelería: $10,08 \%$

- Simple cartón: $27,7 \%$

- Otros elementos: 3 de 119 (luz o stopper)

- Cartón: 71,6\%

- Madera: 1 de 119

- Otros: $22,7 \%$

- Elementos combinados: $15,1 \%$

- Circuito: $17,65 \%$

- Fija: $13 \%$

- Temporal: $87 \%$

\section{Propuestas para una optimización de la PLV}

PLV interactividad: este elemento surge a partir de los soportes multimedia que sectores como el de los videojuegos ya tienen entre sus PLV. Existe un tipo de interactividad directa en el que el consumidor puede tocar las pantallas y "jugar" con ellas y por otro lado también se puede interactuar a través de redes a distancia como SMS o Bluetooth. Esta última forma es una gran oportunidad para los anunciantes de crear una base de datos con la que posteriormente se pueden realizar acciones de marketing directo.

En este caso la PLV digital deja de ser un mero soporte y se convierte en una línea de comunicación entre consumidor y anunciante creando aparentemente mensajes individualizados que el individuo acepta de mejor grado. Es por ello que las opciones multimedia ofrecen mucho más impacto aunque el coste aumente de un simple display de cartón. 
Generar vivencias: de esta forma la fidelización del consumidor es mucho más efectiva, además creamos una marca inconfundible que nos diferenciará del resto de la competencia. Se generan a través de la recreación de ambientes que crean unos lazos afectivos y emocionales estableciendo una vinculación con la marca.

Si un consumidor va a la pescadería a comprar mejillones y entre varias marcas hay una cuyo producto viene presentado es un barco que recrea la pesca del molusco y que además lo acompaña una caracola con la que puedes escuchar el sonido del mar, probablemente el consumidor se sentirá más atraído por el productos asociándolo a valores como fresco, puro o de calidad.

El objetivo de toda PLV debe ser llamar la atención de los clientes y potenciar la interactividad con ellos aumentando de esta forma el recuerdo y por lo consiguiente, los impactos finales.

La exhibición ya no es suficiente, la experiencia es lo que transmite al consumidor. La PLV no debe ser un simple contenedor, sino un hilo conductor de un sinfín de sentimientos. 